\section{Diet and The Milk Drip}

By Rose Simmonds, S.R.N.

Chief Dietitian, Hammersmith Hospital. Editor, 'Nutrition, Dietetics and Catering'

The amount of milk given in 24 hours with the milk drip varies from two to five pints. The caloric value of five pints of milk is 1900 , rather more, in fact, than half the patient's needs. In order therefore to satisfy his requirements in full, various types of fortified milk mixtures are required and with these a properly balanced diet may be easily achieved. Eggs, butter, dried milk, glucose and casinal can be added to give the necessary balanced calorie intake, whilst vitamins, salt and iron supply other essential factors.

Well-beaten eggs, not more than one per pint of the mixture, supply protein and fat ; butter melted in the mixture adds fat ; dried milk adds carbohydrate, protein and fat; casinal (Glaxo) is very useful in providing pure and suitable protein (26 gm. per ounce of casinal), whilst the carbohydrate requirements are easily met by the addition of sugar, glucose or lactose.

Such a mixture is deficient in salt and in iron. These two substances are, therefore, added, one teaspoonful of salt and one ounce of Mist. Ferri et Ammon. Cit. daily being adequate. Vitamins are added as thought fit, the routine recommended being to add a compound vitamin $B$ preparation such as Benerva (2 tablets), ascorbic acid (200 mgm.) and cod liver oil ( 2 teaspoons) daily to the feeds. This will more than cover the daily vitamin requirements, namely, vitamin A, 5,000
I.U.; aneurin, 600 I.U.; riboflavin, $2.7 \mathrm{mgm} . ;$

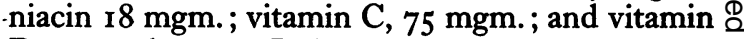
$\mathrm{D}$, more than $400 \mathrm{I}$.U.

Mixtures so. fortified should always be put $\vec{\theta}$ through a fine strainer before use and should be put into the reservoir flask (preferably of $\vec{\omega}$ Thermos type) at $100^{\circ} \mathrm{F}$. From time to time the flask should be stirred to prevent coagulation. In hot weather it is wise to citrate the feeds by the addition of sodium citrate ( 2 teaspoons to $N$ the pint). More eggs or larger amounts of dried $\dot{c}$ milk than those recommended in the diets below will be found to make the mixtures too thick, blocking the drip or the tip of the Ryle's tube ; the content is, therefore, better diluted by increasing the bulk of fluid. It is wise, in any case, to disconnect the drip from time to time and to syringe it through with water.

For most patients requiring a milk drip, the specific requirements will be best met by giving a calorie intake equivalent to that required for $\overrightarrow{0}$ moderate activity, that is, slightly more than required to maintain the body weight whilst in bed. For a man of average size suffering from a duodenal ulcer, therefore, the fifth mixture below should be adequate and should cause an increase in weight. To counteract the constipating effect of such a diet, liquid paraffin as necessary, perhaps $\frac{1}{2}$ ounce t.d.s., is recommended.

With a cooperative patient such a drip may be well tolerated and may be continued for an indefinite period.

It is hoped that the following tables of nutritive values and basal requirements may be helpful. 
BASIC MILK MIXTURES FOR THE DRIP METHOD OF FEEDING

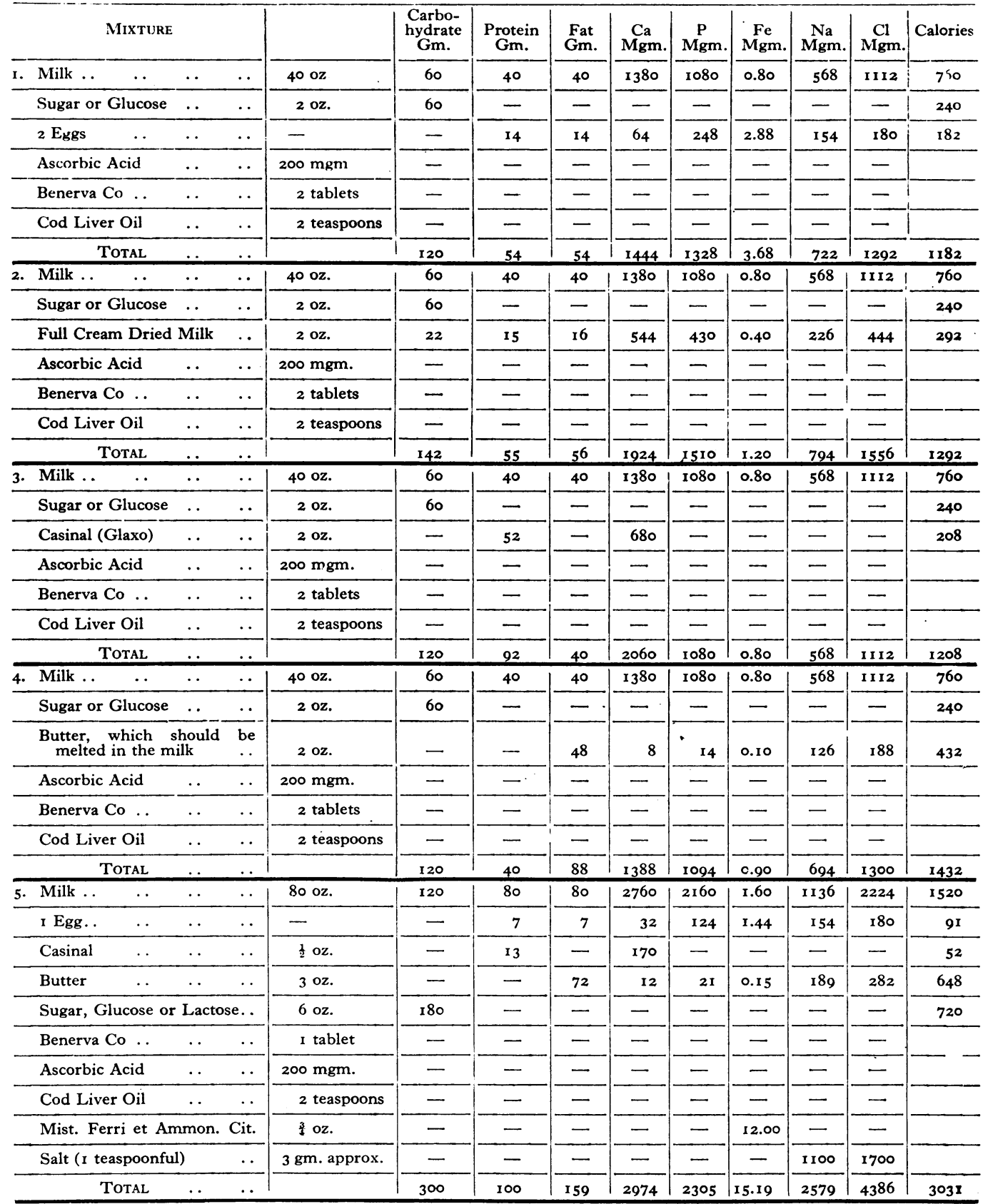

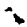

COMPARE DAILY REQUIREMENTS

\begin{tabular}{|c|c|c|c|c|c|c|c|c|c|c|c|c|}
\hline Moderately acti & $\operatorname{man}$ & $\cdots$ & - & - & 70 & - & 800 & - & 12 & 1940 & 2830 & 3000 \\
\hline , & woman & .. & - - - & - & 60 & 一 & 800 & 一 & 12 & 一 & 一 & 2500 \\
\hline Active man .. & . & .. & 一 & - & 70 & 一 & 800 & - & 12 & - & - & 3600 \\
\hline woman & .. & $\ldots$ & - & - & 60 & - & 800 & - & 12 & - & - & 3000 \\
\hline
\end{tabular}

